\title{
REFLEXÕES SOBRE O FASCISMO E A VIOLÊNCIA NO BRASIL: A SITUAÇÃO DAS CLASSES TRABALHADORAS NO MOMENTO DE CRISE ORGÂNICA DO CAPITAL.
}

\author{
REFLEXIONES SOBRE EL FASCISMO Y LA VIOLENCIA EN BRASIL: LA SITUACIÓN DE LAS \\ CLASES TRABAJADORAS EN EL MOMENTO DE LA CRISIS ORGÁNICA DE LA CAPITAL
}

\begin{abstract}
REFLECTIONS ON FASCISM AND VIOLENCE IN BRAZIL: THE SITUATION OF THE WORKING CLASSES IN THE MOMENT OF ORGANIC CRISIS OF THE CAPITAL
\end{abstract}

DOI: http://dx.doi.org/10.9771/gmed.v11i2.33949

\author{
Anita Helena Schlesener ${ }^{1}$ \\ Gilson Mezzaroba² \\ Tariani Maria Garcia de Almeida ${ }^{3}$
}

Resumo: Este artigo tem o objetivo de fazer algumas observações sobre o fenômeno mundial de ascensão de movimentos reacionários que retomam símbolos fascistas e nazistas e como estas ideologias se apresentam no Brasil, nas várias formas que assume a violência urbana e rural. Retomamos alguns aspectos da atual fase da luta de classes, que entendemos como uma ostentação de um comportamento violento e preconceituoso, enquanto parte de uma política conservadora e repressiva num momento de grave crise financeira, que se estendeu dos centros capitalistas para a periferia, acompanhando as vias de internacionalização do capitalismo. Fazemos um esboço das raízes clássicas do fascismo para explicitar suas formas no atual momento histórico.

Palavras-chave: fascismo, violência, história, educação.

Resumen: Este artículo tiene como objetivo hacer algunas observaciones sobre el fenómeno mundial del surgimiento de movimientos reaccionarios que retoman los símbolos fascistas y nazis y cómo estas ideologías se presentan en Brasil, en las diversas formas que asume la violencia urbana y rural. Hemos retomado algunos aspectos de la fase actual de la lucha de clases, que entendemos como una muestra de comportamiento violento y prejuicioso, como parte de una política conservadora y represiva en un momento de grave crisis financiera, que se ha extendido desde los centros capitalistas a la periferia, acompañando formas de internacionalización del capitalismo. Esbozamos las raíces clásicas del fascismo para explicar sus formas en el momento histórico actual.

Palabras clave: fascismo, violencia, historia, educación.

Abstract:: This article aims to make some observations about the worldwide phenomenon of the reactionary movements that retake fascist and Nazi symbols and how these ideologies present themselves in Brazil, in the various forms that urban and rural violence. We have resumed some aspects of the current phase of the class struggle, which we understand as a display of violent and prejudiced behavior, as part of a conservative and repressive policy in a time of serious financial crisis, which has spread from the capitalist centers to the periphery, accompanying ways of internationalization of capitalism. We outline the classic roots of fascism to spell out its forms in the present historical moment.

Keywords: fascism, violence, history, education.

\section{Introdução:}

Sentir a revolução dos dois lados: ou então, mostrar que as coisas não são tão "seráficas" nem tão "lucíferas" quanto alguns tentam fazer parecer (BAUDELAIRE, 1995). 
Este artigo tem o objetivo de fazer algumas observações sobre a violência no Brasil, entendendoa como parte da estrutura da sociedade moderna, visto que esta tem como pressuposto a exclusão na medida em que se organiza a partir da divisão social do trabalho e da competição permanente entre os grupos que a compõem. Para além de toda justificação, a violência assume vários significados a partir de como a dominação se concretiza na sociedade capitalista: a realidade de exploração da força de trabalho é violenta, assim como a fome, a miséria, as condições desumanas às quais são reduzidos os trabalhadores no mundo inteiro. O direito moderno oculta a violência de um poder que se engendra como dominação, ao concentrar nas instituições policiais e militares do Estado o direito de controlar e punir, controle e punição que recaem sempre sobre as classes trabalhadoras, a maioria que é submetida à ordem pensada e produzida pela classe dominante.

Se tomarmos o conceito na sua relação com as estruturas de poder a partir da formulação de pensadores clássicos, vemos que a violência permeia a formação social e política: já no século XVI Maquiavel nos lembrava que a violência faz parte da estrutura de poder, mostrando com muita clareza como os conflitos devem ser equilibrados com a formação do consentimento das massas para que o exercício do poder se legitime e possa se consolidar por algum tempo. A partir do século XVII intelectuais como Grócio, Pufendorf, Hobbes, Locke, Rousseau, dedicaram-se a explicitar a existência da violência na formação da sociedade defendendo a celebração de pactos ou contratos para regulamentar o convívio social a fim de superar as tensões e conflitos. Hobbes é uma referencia muito conhecida, que acentua que, para evitar a destruição mútua e a situação de permanente insegurança e medo, os homens precisaram organizar-se em sociedade e transferir para o Estado o monopólio da força. Os pressupostos de Hobbes são retomados por Weber na explicação das tarefas do Estado.

A guerra é uma forma de violência bruta que penaliza principalmente as classes populares, mas a elite intelectual descrita por Benjamin nas Teorias do Fascismo Alemão acentua que o Estado tem a tarefa de controlar a guerra, não para fins pacifistas, mas para mobilizar as "forças mágicas" para os fins da dominação, da manutenção das relações de produção e da propriedade (BENJAMIN, 1985, p. 65). O fascismo alemão, assim como as guerras imperialistas, nada tem a ver com pacifismo, afirmação que só pode ser feita por quem faz a guerra e não por aqueles que a sofrem. "Contra-ataques aéreos por meio de gases não existe, ao que se sabe, nenhuma defesa eficaz" (BENJAMIN, 1985, p. 63). A violência da guerra toma a forma de terror, genocídios, violências que dizimam populações sem que se faça o seu inventário. A história do século XX foi, na leitura de Hobsbawm (1995), uma história de muitas guerras resultantes das disputas de espaços geopolíticos para assumir o controle e o comando da economia mundial, ampliar domínios econômicos e ideológicos. E este início de século não parece anunciar mudanças significativas.

Estamos diante de um fenômeno mundial de ascensão de novos movimentos reacionários que retomam símbolos fascistas e nazistas portando bandeiras antigas das políticas conservadoras e que tentam se beneficiar de uma profunda crise de hegemonia; esta se manifesta tanto como crise econômica quanto como descrédito das instituições políticas e da atuação dos dirigentes das classes dominantes, ao mesmo tempo em que os grupos de esquerda, fragilizados por suas histórias políticas, não conseguem organizar-se unitariamente para enfrentar o conservadorismo ascendente. 
Retomamos alguns aspectos da atual fase da luta de classes no Brasil, que entendemos como uma ostentação de um comportamento violento e preconceituoso, enquanto parte de uma política conservadora e repressiva num momento de grave crise financeira, que se estendeu dos centros capitalistas para a periferia, acompanhando as vias de internacionalização do capitalismo. As mudanças implementadas por uma política neoliberal para enfrentar esta situação acentuaram as formas de exploração do trabalho e geraram um aumento da desigualdade social que, chegando a uma situação extrema, torna-se insustentável.

Quais os elos que podemos encontrar entre o fascismo europeu da primeira metade do século $\mathrm{XX}$, que foi uma experiência datada e vencida em seu tempo, e o que chamamos de fascismo no Brasil? Sabe-se que o fascismo tinha vínculos claros com o capitalismo monopolista da época, num momento em que a economia, passando por uma de suas crises, precisava do respaldo do Estado para a retomada da reprodução ampliada do capital. Este fato torna o fascismo datado. Como entender seu retorno e suas novas características no contexto de mundialização do capital, agora na fase de financeirização da economia?

Trata-se de um novo momento no qual se erguem, em todos os cantos do mundo, organizações de direita que reivindicam os pressupostos daqueles movimentos radicais conservadores: as mesmas bandeiras e símbolos, porém novos contextos de formação ideológica que reprimem diferenças individuais, visam conter o processo migratório com acentuadas características xenófobas e nacionalistas. O Brasil, nesta fase de capitalismo imperialista, com uma história política e cultural de raiz conservadora, com breves períodos de frágil democracia burguesa, tornou-se o espaço do irracional, da apologia da violência e da ofensiva contra as esquerdas e os movimentos sociais. A situação aviltante à qual se encontram reduzidas as classes trabalhadoras se expressa na violência urbana que visa a resolver o problema social da miséria por meio da repressão e da chacina de jovens negros e pobres. No meio rural, na repressão violenta e sistemática aos que lutam pela terra, camponeses e índios, repressão levada a cabo com a conivência do Estado. A esta situação se acrescentam as tentativas de tolher a liberdade de ir e vir e de escolha autônoma garantidas pela Constituição brasileira, com tiros, pedras e chicotes. O índice de feminicídios e de violência contra a mulher dispara nas estatísticas. 2018 e 2019 traz a mancha do sangue de centenas de dirigentes de movimentos populares.

A violência ostensiva e a violência psicológica, exercidas cotidianamente sobre os grupos subalternos: a mulher, a criança, o pobre, o negro, o índio, se considerados no seu conjunto, formam a maioria da população. A partir das medidas antissociais do governo, da volta do Brasil ao mapa da fome e do aumento do desemprego, o cenário que se anuncia é de aumento da repressão policial contra as populações pobres com o objetivo de concretizar a agenda neoliberal implementada.

O fascismo afirma-se como uma visão de mundo não ideológica, ou seja, neutra, mas, como todas as relações em uma sociedade de classes, também ele é uma ideologia, com uma função política determinada na realidade brasileira, que é a de acirrar o conflito social a partir do exercício da violência contra os grupos que a ele se opõe ou que pensam diferente dele. Do ponto de vista da direita (fascismo ou neoliberalismo), a ideologia é a dos outros; entretanto, considerar a realidade do mercado como ahistórica e não determinada socialmente também se constitui em ideologia. Não existem relações naturais e eternas que não sejam reguladas pela política, isso em qualquer tempo ou lugar. Este discurso, porém, disseminado no senso 
comum dilui a luta de classes e mantém as bases de subalternidade das classes populares em relação à hegemonia vigente, tornando difícil a organização política e a elaboração de uma nova concepção de mundo capaz de pensar e lutar por uma sociedade diferente desta que estamos vivendo.

O aporte teórico é o pensamento gramsciano, a partir da crítica e da resistência de Antonio Gramsci ao fascismo, que enfrentou com determinação de jornalista livre que, em 1931, quinto ano de sua prisão, escreveu: "Eu nunca fui um jornalista profissional, que vende a sua pena a quem pagar melhor e deve continuamente mentir, porque a trapaça entra na qualificação profissional. Fui um jornalista muito independente, sempre de uma única opinião e nunca escondi minhas convicções profundas para agradar patrões" (GRAMSCI, 1978, Carta de 12/10/1931). Gramsci combateu ferrenhamente o fascismo italiano tendo morrido em cárcere fascista.

O fascismo se apresentou como antipartido, abriu as portas a todos os candidatos e, com sua promessa de impunidade, deu a uma multidão impopular a cobertura vaga e nebulosa de um verniz de idealidade política ao selvagem transbordar das paixões, dos ódios, dos desejos. O fascismo tornou-se, assim, um fato de costume, identificou-se com a psicologia bárbara e antissocial de algumas camadas do povo italiano ainda não modificados por uma nova tradição, pela escola ou pela convivência em um Estado bem ordenado e bem administrado (GRAMSCI, 1978b, p. 150).

Estas características levantadas por Gramsci podem ser identificadas na realidade brasileira, nos costumes e preconceitos de fundo autoritário e repressivo que se consolidam a partir das relações familiares e religiosas de determinados grupos sociais. Não se trata de um movimento organizado em partido, mas de manifestações dogmáticas e diluídas que defendem o fim de direitos e a ditadura militar, concretizando-se, aos poucos, em violência bárbara contra os sem-teto, os moradores de rua, a favor do estupro e outras manifestações irracionais. Em alguns Estados a violência tomou as ruas com a conivência do poder instituído, visto que o Estado não coíbe a sua própria polícia.

Pretende-se primeiramente apresentar um esboço das raízes clássicas do fascismo, basicamente o italiano, acentuando as formas como este fascismo se apresenta no atual momento histórico, acrescido da atuação sistemática da mídia na formação de um pensamento único e demonizador das esquerdas no Brasil.

Em seguida salientamos aspectos gerais da história política brasileira, a fim de mostrar que o momento atual expressa a eclosão de forças reacionárias mantidas nas sombras ao longo dos interstícios de frágil democracia.

Finalmente, pretende-se destacar como a atual forma neoliberal de gestão política expressa-se em politicas públicas conservadoras, que retiram direitos historicamente consolidados e reduzem as classes trabalhadoras a uma massiva subalternidade, sem condições a curto prazo de reagir e resistir.

\section{Notas para uma caracterização geral do fascismo:}

É destino que a morte da burguesia coincida também com o desaparecimento de todos os valores de moralidade e de coragem. Neste sentido, os fascistas são bons agentes funerários (GRAMSCI, 1978b, p. 191). 
Trata-se de levantar algumas características gerais, sem a pretensão de uma genealogia ampla de um movimento conservador reacionário que tomou várias formas na história política moderna. Trata-se de explicitar a natureza do fascismo enquanto organização reacionária e autoritária, de fundo pragmático, que se organiza em um partido político de massa alimentado por uma ideologia que visa a impor uma visão de mundo por meio da violência. Se partirmos do fascismo de Mussolini, na leitura de Konder (2009, p. 60), "Mussolini extraiu de Sorel muitos aspectos de sua concepção de violência", assim como teve a influência da ideia de super-homem de Nietzsche. Mussolini também retomou dos romanos a ideia de fascio ou feixe, símbolo que marcou o movimento italiano e orientou a organização de células ou grupos disciplinados e organizados para ações violentas. Estas mesmas células, com fim disciplinar e educativo, desdobraram-se em escolas destinadas principalmente a formar um exército de fieis adestrados na defesa do movimento. Ainda na leitura de Konder (2009, p. 67), os "fasci di conbattimento não tinham programa: limitavam-se a vomitar impropérios pretensamente patrióticos contra os inimigos", usando sempre da força bruta. A truculência do movimento orgulhava Mussolini.

Para De Felice (1978, p. 211), o fascismo surgiu como uma força conservadora das contradições internas do capitalismo, de sua necessidade de vencer uma crise orgânica, crise de hegemonia, e fazer frente ao processo de organização do proletariado, ou seja, o fascismo apareceu como “expressão específica, historicamente determinada, de um processo mundial”. Partindo do referencial gramsciano, De Felice acentua que a compreensão da especificidade do fascismo, "da sua dinâmica interna, da transformação dos instrumentos políticos e institucionais de direção e de domínio, não pode ser separada da apropriação de um processo internacional".

De Felice (1978, p. 215) acentua ainda que "uma contribuição de excepcional importância dada por Gramsci no período de 1921-22" sobre a ascensão do fascismo foi mostrar "a indissolubilidade de dois fenômenos, a dissolução do Estado liberal e a emergência de novas formas de agregação e dominação política", com um elemento novo que era a sua “dimensão social e de massa”.

O fascismo é visto por Gramsci como um aspecto e um elemento da dissolução do Estado liberal, enquanto parte do desenvolvimento da sociedade civil a expressão da insubordinação da pequena-burguesia, e ao mesmo tempo como instrumento para reconstituir sobre novas bases a dominação dos latifundiários e dos industriais questionada pela ofensiva operária (DE FELICE, 1978, p. 215).

Destas colocações emanam algumas características próprias do fascismo italiano que repercutem nos movimentos conservadores brasileiros: o patriotismo, na apropriação dos símbolos nacionais, no combate a um comunismo imaginário, na incompreensão e na obtusidade expressa no fato de que os novos fascistas não entendem que nos encontramos numa nova fase histórica de expansão e mundialização do capitalismo. Nos bastidores destes movimentos, fortalece-se o latifúndio, cujos interesses são defendidos e ampliados. A partir desta característica, tem-se a demonização da esquerda, visto que esta defende o internacionalismo expresso no projeto socialista. Demoniza-se ainda o comunismo e seus símbolos, como a bandeira vermelha, a foice e o martelo (que sempre foram entendidos como instrumentos de trabalho e não como instrumentos de opressão) como se o comunismo fosse uma ameaça iminente. Desta forma, a esquerda se torna o alvo principal da violência sistematizada, embora esta também se volte para as classes 
trabalhadoras em geral, principalmente na escalada da violência urbana e rural. Manifesta-se aqui a característica fundamental do fascismo que é o uso da força bruta para calar, não importa se com a morte, aquele que pensa diferente dos dogmas conservadores. Cancelam, matam, tolhem a liberdade de movimento e de expressão dos que se opõe ao seu projeto.

No caso do fascismo italiano, a classe social de base deste movimento era a pequena burguesia nos centros urbanos e os proprietários rurais no campo, onde ocorria o confronto com o movimento camponês organizado. Esta identidade de classe fica mais diluída no caso brasileiro, embora o discurso conservador seja a bandeira das classes médias, que levam consigo parcelas significativas das classes trabalhadoras, as quais formam seu modo de pensar a partir do pensamento único divulgado pelos meios de comunicação de massa. A partir do ideário neoliberal divulgado como verdade absoluta, as classes trabalhadoras, que nunca foram tão numerosas quanto neste início de século, não se reconhecem como classe e, assim, podem aderir a movimentos conservadores inclusive contra os seus interesses sociais.

Outra característica do fascismo foi “desencadear as forças elementares incontroláveis" da sociedade: o "fascismo é o nome da profunda decomposição da sociedade italiana", concomitante `a “profunda decomposição do Estado", que só podem ser entendidas a partir do "baixo nível de civilização da nação italiana" (GRAMSCI, 1978b, p. 150). No Brasil, estas forças emergiram das sombras, fruto de uma história de autoritarismo e de educação repressiva, na forma do ódio, do preconceito mais feroz.

Outra semelhança que se pode levantar entre o fascismo clássico e o brasileiro é a confusão de conceitos, de modo a parecer que todas as ideias estão fora de lugar. Nos movimentos conservadores em geral, também nos mais violentos como o fascismo, as questões políticas não são tratadas como tais, mas são tratadas como questões morais ou como "fatos de costume", como acentua Gramsci; no caso brasileiro, a denominada "ideologia de gênero", a religião e a família, todas instâncias indiretamente políticas (visto que na sociedade de classes tudo tem conotação política), são transformadas em questões morais, de preservação de valores naturalizados.

Esta característica se acentua pelo uso ou a instrumentalização das ideias, ou seja, o fascismo é uma ideologia que não se reconhece como tal e acusa todas as outras formas de pensamento como ideológicas. Para Konder (2009, p. 78), o “fascismo é uma revolta contra o materialismo histórico, é uma reativação apaixonada das convicções idealistas". Tais convicções se apresentam como valores morais universais que os subalternos precisam assimilar para adequarem-se aos objetivos do mundo do trabalho. Assim como os camisas negras italianos, o movimento reacionário brasileiro se apropriou dos símbolos nacionais e as armas usadas são a força bruta para tolher as liberdades de expressão e de movimento dos que pensam diferente.

Por último, o voluntarismo, ou seja, a valorização de um líder que, no discurso e na prática, assume uma posição autoritária e impositiva, tendendo para a implantação de uma ditadura. A personalização do líder dilui o esforço de organização coletiva das classes trabalhadoras, que não se entendem como classe e vivem a mais profunda alienação política. Dissolvida a identidade de classe, dilui-se também a compreensão da luta de classes que, como acentua Dias (2014, p. 27), “é exercida clandestinamente: é a forma pela qual hábitos, saberes e costumes dos dominantes assumem o caráter de horizonte ideológico". No dia a dia das 
classes trabalhadoras, os meios de comunicação de massa acenam com a beleza "das formas de vida dos dominantes", passados "para os dominados como as únicas formas possíveis de pensar, agir, sentir, elaborar conhecimentos e estratégias".

Existem outras características que poderiam ser elencadas, mas a que mais repercute na formação do senso comum é a aliança entre uma prática violenta e repressiva em relação ao novo e ao diferente com a religião, em todas as formas que esta assume na contemporaneidade. As religiões têm sido a mais forte ideologia em confronto com as formações de esquerda no Brasil. A ideia de um sofrimento consentido, de uma realidade naturalizada e sem história e que, portanto, não se pode mudar, são mais um dos elementos constitutivos da luta de classes e afetam diretamente a formação de uma consciência política emancipadora. Acrescente-se a este conjunto de elementos uma formação liberal que desconsidera a importância de um coletivo para valorizar o individual subjetivo, na ideia de livre arbítrio. Estas características de nossa tradição formativa fazem com que este horizonte ideológico fortaleça movimentos conservadores, que expandem sua ideologia pelas redes sociais e pelos meios de comunicação de massa, exercendo forte influência sobre a classe trabalhadora.

Neste contexto, a violência física e simbólica enquanto repressão aberta ou velada ao diferente, transforma-se em "padrão ético, eterno e universal de comportamento" que, usando da força bruta contra os que não consentem, bem como da chantagem afetiva, conforma a maioria ao "horizonte subjetivo dos dominantes" e predispõem “as classes trabalhadoras à servidão voluntária” (DIAS, 2014, p. 28-29). Portanto, o fascismo no Brasil nos dias atuais, além do seu significado político visto que tudo é política (também a religião e todas as formas de ideologia), tem uma conotação diversa dos movimentos reacionários que ascendem na Europa, onde as ações violentas se voltam contra o imigrante e tem como pano de fundo não apenas a questão econômica do mundo do trabalho, mas o medo disseminado da islamização da sociedade; na nossa realidade o fascismo se amplia por sua influência ideológica na formação do comportamento agressivo e violento em relação aos pobres e negros, aos individualmente diferentes e, principalmente aos que pensam de uma forma crítica.

\section{Notas sobre a história política brasileira:}

A organização política supõe autoeducação: precisamos estudar para melhorar nossa capacidade de luta e para compreender nossas posições e as posições do inimigo, para traduzir tudo isso em ação (GRAMSCI, 1978b).

$\mathrm{Na}$ historia política brasileira tivemos, em alguns momentos, fenômenos de conotação moral conservadora, que não se caracterizam como fascismo nos moldes da experiência italiana, embora possamos levantar algumas semelhanças, como símbolos, atitudes, disciplina e, evidentemente, a reação antiproletária e anticomunista, principalmente nos momentos de recrudescimento das ditaduras, civis ou militares, que grassaram o nosso país com certa frequência, assim como ocorre também no continente latino-americano. Se pensarmos no período Vargas, a semelhança de atitudes, da ideologia presente nas cartilhas escolares, da aproximação com o eixo durante a II Grande guerra, permitem falar em fascismo. 
Conforme Weffort (1978, p. 52-53), o fim da ditadura de Vargas em 1945, “concomitante com o fim da guerra contra o fascismo com o qual era confundida, parecia significar o fim do fascismo no Brasil e unia, portanto, amplos setores urbanos”. Segue-se um processo de construção de uma democracia de massas, mas marcada pelo populismo, tendo o Estado como organizador e mediador, de modo que "todas as organizações importantes que se apresentam como mediação entre o Estado e os indivíduos são antes anexos do próprio Estado que órgãos efetivamente autônomos". Controlada deste modo, a democracia no Brasil se apresenta frágil e, cada vez que os movimentos populares se organizam ou se levantam para reivindicar mudanças, a democracia passa a ser ameaçada.

De acordo com Fernandes (1981), mesmo no interior de regimes democráticos pode-se encontrar traços de estruturas e dinamismos fascistas, pois, se Hitler e Mussolini foram derrotados no campo de batalha o mesmo não se pode afirmar do fascismo que, como ideologia, persiste ainda como poderosa força política. Nossa história foi marcada por eventos autoritários, de períodos de dominação portuguesa, de uma república decidida pelo alto, de frágeis democracias intercaladas de longas ditaduras. Desse modo, as bandeiras reacionárias do presente expressam as forças retrógradas adormecidas durante períodos de transição lenta e gradual para a democracia. No caso de 1964, tivemos uma transição que se fez "pelo alto", pois os militares saíram da linha de frente das responsabilidades pela direção do Estado, deixando o poder em mãos que consideravam confiáveis e o povo, em geral, continuava à margem desse processo, condição expressa nas eleições indiretas.

Para Germano (2011), no Brasil, a partir de 1964, o Estado caracterizou-se pelo elevado grau de autoritarismo, violência e pela manutenção de uma aparência democrático-representativa, uma vez que o congresso não foi fechado definitivamente (embora tenha sido mutilado) e o Judiciário continuou a funcionar, ainda que como apêndice do Executivo. Contudo, o autoritarismo traduziu-se pela tentativa de controlar e sufocar amplos setores da sociedade civil, intervindo em sindicatos, reprimindo e fechando instituições representativas de trabalhadores e estudantes, extinguindo partidos políticos, bem como pela exclusão do setor popular e dos seus aliados da arena política.

Mas o que caracteriza a ideologia fascista em todas as épocas não é apenas o autoritarismo explícito ou latente de um poder sempre instituído pelo alto, mas a repressão continuada cujos sinais ficam no comportamento, nas atitudes, no moralismo resultante de uma educação conservadora. O golpe de Estado de 1964 e a subsequente Ditadura Militar firmaram a perspectiva de que a segurança nacional contra o comunismo, seu inimigo maior, deveria ter como fundamento a garantia de valores que resguardassem a nação das investidas contrárias aos fundamentos da família, da pátria e da propriedade, valores que passaram a ser orientados pela Escola Superior de Guerra (ESG).

Do ponto de vista de Gramsci, a educação repressiva, repressão que não é apenas a violência explícita, no ataque ao diferente, ao mais fraco, mas é também a censura, o silencio, a vigilância contínua que, interiorizados, transferem para a nossa subjetividade o controle que a ordem nos impõe. Sofrem cotidianamente os filhos das classes trabalhadoras que, sem ter garantidos o conjunto dos direitos fundamentais, sem espaços de socialização ou de formação para sua inserção social no âmbito da ordem instituída, são envolvidos pelo crime organizado, pelo tráfico de drogas, situação que os leva a um confronto 
permanente com as forças da ordem e com a barbárie de cárceres superlotados. Esta educação repressiva de jovens pobres e negros torna-se visível nos momentos em que recrudesce o conservadorismo, nos momentos em que a classe dominante, vendo ameaçados seus privilégios, demonstra todo o seu poder repressivo na violência armada. Sofremos esta situação por mais de vinte anos e a saída lenta e gradual da ditadura para a democracia liberal conservou os ranços daquele período, que marcam a formação que recebem as novas gerações.

\section{Notas sobre as políticas públicas num contexto de arbítrio:}

O mundo ao avesso gratifica o avesso: despreza a honestidade, castiga o trabalho, recompensa a falta de escrúpulos e alimenta o canibalismo (GALEANO, 1998)

No contexto da democracia brasileira, na medida em que o capitalismo imperialista se expande internacionalmente e o neoliberalismo se apresenta como política e como ideologia orientadora do modo de pensar e de sentir da sociedade, a burguesia demonstra sua força conservadora e reacionária tolhendo os direitos historicamente conquistados pelas classes populares com políticas recessivas. Com um congresso sem representatividade social, mas defensor do poder econômico, as políticas públicas fazem apenas reproduzir e fortalecer a ordem instituída. A força policial e o autoritarismo se impõem ante as reivindicações populares.

A igualdade jurídica formal mascara a luta de classes, que acontece no cotidiano em todas as instâncias do social; "apresentada como algo demoníaco, inventada pelos que querem destruir a vida social, seus promotores são acusados de comunistas" (DIAS, 2014, p. 25); esquece-se que a "luta de classes, como dizia Gramsci, não está sendo proposta pelas forças de trabalho, mas imposta exponencialmente pelo capital" e as classes trabalhadoras não têm outra alternativa senão confrontar-se (DIAS, 2014, p. 27).

As aspirações politicas num contexto de arbítrio não se efetivam por políticas públicas que, nos limites em que são produzidas, apresentam um efeito apenas paliativo, compensatório, sem possibilidades de mudanças estruturais efetivas. A maioria destas políticas apresentam o objetivo de consolidar a ordem instituída e formar por meio de valores conservadores.

A ideologia fascista se consolida pela educação ou por uma cultura do terror (GALEANO, 2002), que se dissemina no processo educativo originado na família e estendido posteriormente para a orientação dada por políticas conservadoras. O golpe militar de 1964, acompanhado pela formação de lideranças pela ESG, pelas políticas educacionais consolidadas nas disciplinas de OSPB e Educação Moral e Cívica, marcaram as gerações posteriores no conservadorismo que marcou o sistema escolar. Conforme Rezende (2013), a família, a escola, os grupos de pressão, as associações de pais e professores, as associações de mães, a imprensa, o rádio, a televisão, deveriam, segundo a ditadura, ter suas ações e convicções voltadas inteiramente para a construção da ordem, da harmonia, da coesão e da integração nacional. Nesse sentido, a educação tinha que ser estruturada de forma que ela fosse capaz de criar as condições para legitimar o regime o que significava adaptar e ajustar as gerações seguintes aos valores concebidos como essenciais pela 
nova ordem social que estaria sendo criada. A ditadura militar possuía, assim, um projeto de homogeneidade. Logo, a insistência na internalização dos valores patrióticos por meio dos símbolos nacionais fazia parte do seu projeto de legitimidade.

A saída lenta e gradual para uma democracia e as disputas das forças em presença pela instituição da legalidade não conseguiram superar os nuances conservadores que marcaram o processo educativo, visto que mudança de hábitos e costumes na formação do senso comum exigem uma consciência política que só se organizada ao longo de um tempo. A implementação da política neoliberal, avessa a uma efetiva democracia, as alianças políticas assumidas pelo PT em sua gestão, a fim de viabilizar a governabilidade e o recente golpe de Estado de 2016, retomam a implementação de politicas públicas conservadoras, que retiram direitos historicamente consolidados e reduzem as classes trabalhadoras a uma massiva subalternidade, sem condições a curto prazo de reagir e resistir.

À luta dos trabalhadores pela garantia de direitos que estão sendo suprimidos, é preciso aliar a luta contra a homofobia, o feminicídio, o massacre de negros e pobres que vem ocorrendo no Brasil; a alternativa à esquerda com unidade política e unidade dos movimentos populares torna-se urgente para conter o avanço da extrema direita.

\section{Referências:}

BAUDELAIRE, Charles. Ultimi Scritti. Milano: Feltrinelli, 1995.

BENJAMIN, Walter. Teorias do fascismo alemão. In: BENJAMIN, W. Obras Escolhidas - Magia e Técnica, Arte e Política. São Paulo: Brasiliense, 1985.

DE FELICE, Franco. Revolução passiva, fascismo, americanismo em Gramsci. In: FERRI, Franco. Politica e História em Gramsci (Atas do Encontro Internacional de Estudos Gramscianos, 1977). Rio de Janeiro: Civilização Brasileira, 1978, pp. 189-257.

DIAS, Edmundo Fernandes. Notas sobre a hegemonia. In: SCHLESENER, A. H. (Org.) Filosofia, política e educação: leituras de Antonio Gramsci. Curitiba: Ed. UTP, 2014, pp. 19-49.

FERNANDES, Florestan. Poder e contrapoder na América Latina. Rio de Janeiro: Zahar, 1981.

GALEANO. Eduardo. O livro dos abraços. Porto Alegre: L \& PM, 2002.

De pernas para o ar: o mundo ao avesso. Porto Alegre: L \& PM, 1998.

GERMANO, José Willington. Estado militar e educação no Brasil (1964-1985). $5^{a}$ ed. São Paulo: Cortez, 2011.

GRAMSCI, Antonio. Cartas do Cárcere. Rio de Janeiro: Civilização Brasileira, 1978.

GRAMSCI, Antonio. Socialismo e Fascismo - L'Ordine Nuovo 1921-1922. Torino: Einaudi, 1978b.

HOBSBAWM, Eric. Era dos Extremos: O Breve século XX (1914-1991). São Paulo: Companhia das Letras, 1995.

KONDER, Leandro. Introdução ao fascismo. São Paulo: Expressão Popular, 2009.

REZENDE, Maria José de. A Ditadura Militar no Brasil: repressão e pretensão de legitimidade 1964-1984. Londrina: Eduel, 2013.

WEFFORT, Francisco. O populismo na política brasileira. Rio de Janeiro: Paz e Terra, 1978.

\section{Notas:}


${ }^{1}$ Universidade Tuiuti do Parana. Doutora em História, Pós-doutoradoemeducação (UNICAMP). Docente de filosofia política e estetica da UFPR de 1976 a 2005; docente do Mestrado e Doutorado em Educação da UTP. ORCID: https://orcid.org/00000003-2768-5858 Email: anitahelena1917@gmail.com

2 Universidade do Centro do Parana. Docente da UCP. Doutor em Educação pela UTP. ORCID: https://orcid.org/0000-00026071-5572 Email: anitahelena1917@gmail.com

3 Universidade do Centro do Parana. Graduacao em Historia; Mestrado em Ciencia Politica; doutoranda em Educacao pela UTP. Orcid: https://orcid.org/0000-0001-5104-1353 Email: tatianigalmeida@gmail.com

Recebido em 25.10.2019

Aprovado em: 30.10 .2019 